\title{
Electrochromic and Electrochemical Energy Storage Properties of Micro-nano Hierarchical NiO film
}

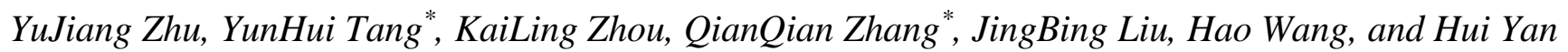

Key Laboratory for New Functional Materials of Ministry of Education, College of Materials Science and Engineering, Beijing University of Technology, Beijing 100124, China.

*E-mail: tangyh@bjut.edu.cn, zhangqianqian@bjut.edu.cn

doi; $10.20964 / 2019.08 .32$

Received: 11 March 2019 / Accepted: 28 May 2019 / Published: 30 June 2019

Micro-nano hierarchical metal oxides offer unique advantages over traditional compact ones when serving as electrode materials, mainly because their good electrolyte wettability and high specific surface area can facilitate fast ion and electron transfer. Herein, we develop a facile route to fabricate micronano hierarchical $\mathrm{NiO}$ films for achieving enhanced bifunction of electrochromism and energy storage. The introducing of hierarchical structure effectively reduced the ion diffusion resistance and electron transfer resistance. As a result, hierarchical $\mathrm{NiO}$ films demonstrate superior electrochromic optical modulation and electrochemical energy storage compared with the compact ones. The transmittance change between the coloration and bleached states reaches $64.5 \%$ at $550 \mathrm{~nm}$. Furthermore, the capacitance of hierarchical $\mathrm{NiO}$ is $14.85 \mathrm{~F} \mathrm{~g}^{-1}$ at $0.2 \mathrm{~mA} \mathrm{~cm}^{-2}$, which is approximately $20 \%$ higher than that of the compact $\mathrm{NiO}\left(12.36 \mathrm{~F} \mathrm{~g}^{-1}\right)$. This work provides an efficient way to prepare high-performance hierarchical NiO films, which can be extended to the fabrication of other metal oxides for wide applications in the highly efficient electrochemical utilization.

Keywords: hierarchical structure, $\mathrm{NiO}$, electrochromic property, energy storage

\section{FULL TEXT}

(C) 2019 The Authors. Published by ESG (www.electrochemsci.org). This article is an open access article distributed under the terms and conditions of the Creative Commons Attribution license (http://creativecommons.org/licenses/by/4.0/). 